\title{
Giant hydronephrosis : a rare cause of gross abdominal distension
}

\author{
AM Abeygunasekera ${ }^{1}$, DVT Harischandra ${ }^{2}$ and ED Udayakumara ${ }^{3}$
}

A 53-year old man was admitted with painless progressive abdominal distension of 1 year duration. $\mathrm{He}$ was a lorry driver and his abdomen started touching the steering wheel, making his job difficult. The abdominal distension was increasing despite treatment for "presumed" ascites. Clinical examination revealed a symmetrically distended abdomen with no palpable masses (Figure1). The swelling was dull to percussion and a fluid thrill could be elicited. But there was no shifting dullness. Ultrasonography revealed a cystic lesion occupying the entire abdomen and pelvis. The left kidney was not visualised. A CT scan showed a large cystic lesion with a normally functioning right kidney (Figure 2). Absence of fluid in the subhepatic space excluded ascites. At laparotomy, a giant hydronephrotic left kidney with a normal calibre ureter was found. Decompression of the kidney yielded 23 litres of dark grey fluid. A left

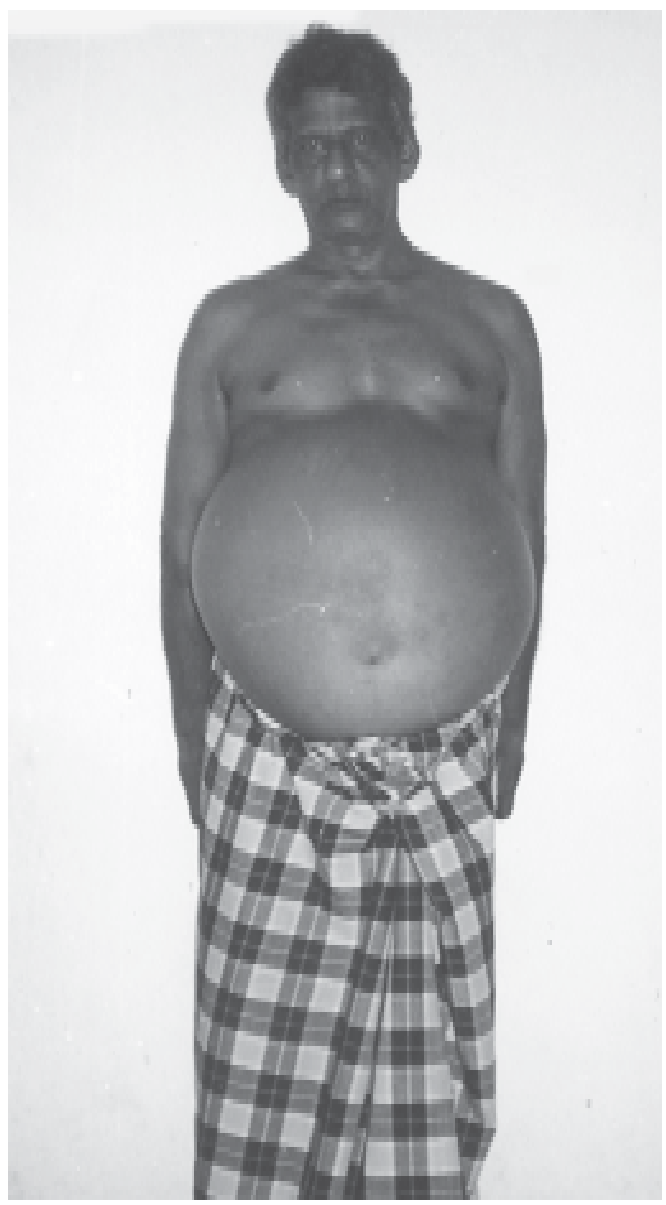

Figure 1. Gross abdominal distension mimicking ascites.

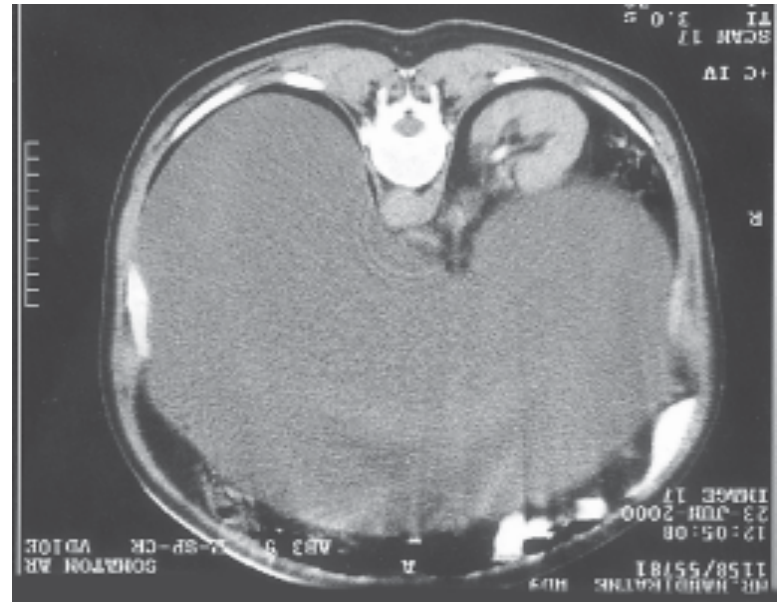

Figure 2. CT Scan showing a large cystic lesion.

nephrectomy was performed. Postoperative recovery was uneventful.

Giant hydronephrosis is defined as a kidney containing more than $1000 \mathrm{ml}$ of fluid in its collecting system [1]. Such a kidney, though rarely, may fill the entire abdomen and pelvis, producing a symmetrical distension of the abdomen. In such a case its differentiation from massive ascites, which is more common, may be clinically difficult [2]. Although there are characteristic ultrasonographic features of a giant hydronephrosis such as a multi-septated cystic lesion with the 'cysts' communicating with one another, accurate preoperative diagnosis can be made only in a proportion of patients [1]. The differential diagnosis includes mesenteric cysts, pancreatic pseudocysts and ovarian cysts [3]. The common causes for giant hydronephrosis are congenital pelviureteric junction obstruction, flap-like mucosal folds and calculous obstruction [2].

\section{References}

1. Singh NK, Jha B, Khanna NN. Giant hydronephrosis masquerading as massive ascites. Postgraduate Medical Journal 1993; 69: 800-2.

2. Crooks KK, Hendren WH, Pfister RC. Giant hydronephrosis in children. British Journal of Paediatric Surgery 1979; 14: 844-50.

3. Talukdar BC, Chatterjee SC, Agrawal TN, De PP. Giant hydronephrosis. British Journal of Urology 1979; 51: $322-3$.

${ }^{1}$ Urological Surgeon, ${ }^{2}$ Registrar, ${ }^{3}$ Senior Registrar, Urologic Unit, Teaching Hospital, Karapitiya, Galle, Sri Lanka. Correspondence: AMA, Tel: +94 112763 427, e-mail: <amabey@sltnet.lk> (Competing interests: none declared). Received 11 September 2003 and accepted 1 January 2004. 